\title{
The library and information field's mass data trend research
}

\author{
WenJun Cai, GuanChun Xu' \\ School of Gannan Medical University, Jiangxi Ganzhou 341000, China \\ 451559971@qq.com
}

Key words: library and information field, mass data, analysis, tendency

\begin{abstract}
Under the mass data background, the library and information field is connected with the mass data more and more closely. To reveal the library and information field's relation with the mass data and its future development trend, the library and information related mass data collected in the CNKI is taken as the major data, and the library and information is set up as the background science to make analysis by using the data collected from related academic essays, by extracting related high-frequency words and by using related software. The analysis results shows that the research topic of the library and information field mainly focuses on the college and university libraries and other 7 groups. The author makes analysis on these groups and draws out the future research trend of the library and information field's mass data.

The new technologies like the things internet and the cloud computing will promote the coming of the mass data age, which causes the internet data quantity and data kinds booms up. The emergence of "Big Data"and"Dealing with Data marks the official arrival of the mass data age. Under the influence of the mass data wave, all industries, represented by the library and information industry, will undergo a revolutionary change, and every corner of the world will be penetrated by the mass data. By taking advantage of this good development chance, many library and information research scholars research the challenges brought by the mass data to the traditional science and research the mass data's application in the library and information field from the angle of the mass data. By far, over 900 mass data and library and information research essays can be found on the China national knowledge internet's data base. The essays cover broad content and new topics. However, few scholars have made research on the tendency of the library and information field's mass data. Therefore, in the essay, the literature measurement method, internet and content analysis methods and the related software are used to analyze and research the tendency of the library and information field's mass data.
\end{abstract}

\section{Data source and research methods}

The author takes the library information science as the background science, and takes the mass data as the main research word, takes the China national knowledge internet as the data source, and then researches 907 essays after eliminating uncorrelated essays. The retrieval time is February, 2016. In the essay, the literature measurement method, content and social network analysis methods are used to make analysis and research. By using the literature measurement method, the related essay's quantity in the China national knowledge internet is calculated out so as to reveal and research the changing rules of mass data essay quantity. By using the content analysis method, the key words statistics are carried out and the analysis is completed by using related software. And the topic classification is confirmed. Then, the net analysis method is used to analyze the information field mass data so as to show the research tendency of this field.

\section{Data analysis}

\section{Academic attention}

According to the essay statistics data of each year's mass data related essays made by the author, the academic field's attention degree on the library and information field and each year's research situations can be seen. According to the related data statistics, the data research of the library and information field mainly includes 3 stages:

The first stage means the time before 2009. This is because the magazine-Nature officially 
introduced the "mass data" column until 2008 and the "mass data" became hot words until 2009. This stage is the mass data beginning stage. In this stage, only a few related essays exist and the research is mainly focused on the data acquiring and the routine data.

The second stage means the time from 2009 to 2012. During this period, the there are not many academic essays about the mass data, either. However, compared with the first stage, the quantity is greatly increased and the essay content depth is greatly improved. Besides, the mass data has become the key research point in other industries.

The third stage means the time from 2012 to the time when the author makes retrieval. During this period, many essays about the library and information are created and the literature quantity is rapidly increased. Only in 2014, over 400 related essays can be searched out in China national knowledge internet, and the research mainly focuses on the mass data application, the challenges and chances brought by mass data to the library and information development and so on. It is worthy to be noted that in 2012, an essay analyzing the library service under the mass data background is quoted for many times, which shows that the library information field has become the key point that is widely noticed by the academic field.

2 Word frequency statistics analysis

The key words can show the essay content in the simplest and the most direct way. The essay's main content can be concluded based on the high frequency words, which makes the essay analysis results more accurate. In this essay, the author uses SATI software to research the key words and eliminates the words that is not related with the library and information field. According to the final statistics result, it can be seen that library, digital library, data mining, competitive intelligence and related words have become the hot research points.

\section{Social network analysis}

The greatest benefit of the social network analysis is that the key words collinear network can show the connection of the key words and can show the word's significance degree. Based on the key word network, the key words can be connected together by the lines to show their relations. The lines quantity and thickness can reflect the connection and relative degree of the key words. If a key word is connected with many lines, it will have many co-lines with other key words and it can reflect the research content and hot degree in a better way. Through the social network analysis, it can be seen that there are many co-lines among the mass data age, library, college library, data processing, cloud computing, data mining and other key words, which shows that these key words are connected more closely. Meanwhile, this also proves that the research direction represented by these key words has the greatest influence on other research directions, they occupy the center position in the library and information mass data analysis field. It also shows that the researches of these directions have formed a certain scale and they are the core bonds that connect the other research directions. As the statistics of the key word collinear network shall be completed on certain times basis and shall be completed in relatively stable status, when the research is furtherly deepened, the key words in the edge pace can also become the research core part. For instance, the digital library, intelligence library and so on all can become the research focuses in the future.

\section{The theme analysis of the library and information field's mass data research}

1 The application of the mass data in library

In the mass data age, the data will be applied in every corner of the society. The library is a public service organization and it can provide a lot of information for the whole society. Therefore, the library can take this advantage and by using the mass data thoughts, it can make good preparation in advance to embrace the coming of mass data age. This is very significant for the library's resource integration and late development. Represented by Weihong Fan, the authors starts a discussion based on the topic of "what kind of mass data is suitable for the library". They make detail analysis about the library's future data source, the development chances and challenges, and they conclude the future research tendency of this field. In addition, represented by Wenyan Zhang, the authors start the discussion around the topic of "the problems exist in the mass data's application in the library career". They have made analysis based on the immature technology, talents shortage 
and unsafe privacy problems.

2 Data mining, analyzing and processing

In the mass data age, the data mining method is mainly used to collect and process data. It means the process of collecting, processing the data and then finding out the effective data. In the mass data age, large quantity of data comes into our life. The data has large quantity and various kinds which increases the analyzers' work difficulty. Therefore, the data mining method can be used to distinguish the data that has potential values, which is the foundation to carry out the data analysis work. Represented by Wenyi Zhong, the researchers have made discussion and research around the theme of "how can the library carry out data mining and analyzing under the mass data background", and they have made analysis about the data mining and the realization effect. Represented by Zhuqi Li, the researchers have analyzed and researched the mass data mining carried out by the government and their conclusions can help government to make the right decision.

3 The intelligent library under the mass data

In the mass data age, the public library will develop into the intelligent library. After the intelligent library appears, the intelligent librarians and intelligent readers will also appear, which is benefit for the realization of the intelligent city. In addition, the mass data technology and the cloud computing ability will also promote the further development of the library. Meanwhile, these technologies can promote the realization of the information sharing between the library, colleges and universities and the companies. These convenient conditions can not only promote the resource sharing but also promote the achievement of the library personalized service on the maximum content, which also follows the global intelligence development tendency. Represented by Chen Chen, the researchers have made analysis and discussion on the theme of "the connotation of the intelligence library and the demand of intelligence library", and they also have researched about the guarantee measures to achieve the personalized service and intelligence service.

4 The public library under the mass data background

The mass data has brought many benefits to our society and can greatly improve the information workers' work efficiency. The library shall take efforts to follow this development trend, strengthen the information establishment and improve its service quality. However, until the time when the author makes data statistics, not many researches about the public library exist, and the researches are mainly focused on the influence brought by the mass data. All researches are still in the primary stage. Represented by Yan Yang, the researchers have made discussion and researches around the issue of "the mass data environment's influence on the library" and they have considered the issues comprehensively and reasonably. In addition, they also put forward related suggestions to guide the library's future service work.

5 Enterprise competitive intelligence

The mass data has brought great changes and deep influence to every industry, especially to the company. Many researchers have focused on the enterprise competitive intelligence, which has great influence on the enterprise. In the mass data age, the companies acquire information by extracting and processing related data and by guessing out the information. The final data is very benefit for the company development. Besides, by exploring the data that has potential value, the company can get very important information. Only after acquiring the information can the company makes information analysis. The company will find out the good development chances by analyzing the related environment, competitors, strategies. After making research about the "chances and challenges brought by the mass data to the companies”, Xiaobin Huang analyzes the existing problems of the company's data analysis, and points out the future development direction of the company competition. In addition, represented by Jinhong $\mathrm{Wu}$, the researchers also discuss and analyze the "opportunities and challenges faced by the enterprise competitive intelligence in mass data age”, and they propose corresponding strategies according to the company's current problems.

6 The college and university library under the mass data background

The college and university are the talent aggregation place and the university and college libraries always attract many scholars and researchers' attention. In the mass data age, the university 
and college's digital data is the new thing and it is widely favored by the researchers. Therefore, the research of the digital data is much more than the research of the public library. There are many literature about the research of the university and college libraries, and the covered content is very wide. For example, a researcher named Wenwen Zeng analyzes the relation among the mass data thoughts, data acquiring and data analysis and then discusses the problems faced by the university library in the mass data thoughts, data acquiring and data analysis aspects. Jingguang Yang, another searcher adds the mass data study and analysis technology into the college and university library, and propose to use a model in the college and university library, which optimizes the library work.

\section{Conclusion}

Generally, the author discusses the library and information field's mass data research tendency and makes multiple dimensional the statistics and analysis. The author hopes that by using related data analysis, the library and information field's research hot point and tendency can be reflected out and hope that the analysis can help the researchers to master the research direction in a better way. By analyzing related data, it is found out that Chinese researchers mainly focus on the research of mass data age, library, college and university library, data processing, enterprise competitive intelligence, cloud computing and data mining, etc. Through the analysis and statistics of the representative key words and research directions, it can be seen that the researchers have made some achievements in these themes' research. However, by comparative analysis, the research heat of the intelligence library and public library is far enough, and the researches are still in the primary stage. These researches still need to be strengthened in the future. In addition, in China, the library and information field research mainly focuses on the influence brought by the mass data and the research is mainly carried out from the theory analysis aspect. However, there are not many researches about the practice. In the future, the researchers shall strengthen the research about the practice.

\section{References}

[1] Tao Xuejiao, Hu Xiaofeng, Liu Yang. Big data Literature Review [J]. Journal of system simulation, 2013 (S1).

[2] Tu Xinli,Liu Bo,Lin Weiwei. Big according Literature Review[J]. Computer application research, 2014 (6).

[3] Li He, Yuan Cuimin,Li Yafeng. Big data based on bibliometrics research summary [J]. Information Science, 2014 (6).

[4] He Fei,He Keqing. Big data and its scientific problems and methods of discussion [J]. Journal of Wuhan University Acta, 2014 (1). 